II: HARVARD Kennedy School

JOHN F. KENNEDY SCHOOL OF GOVERNMENT

\author{
Faculty Research Working Papers Series
}

\title{
On the Philosophy of Group Decision Methods I:
}

The Non-Obviousness of Majority Rule

\author{
Mathias Risse \\ John F. Kennedy School of Government - Harvard University
}

November 2008

RWP08-064

The views expressed in the HKS Faculty Research Working Paper Series are those of the author(s) and do not necessarily reflect those of the John F. Kennedy School of Government or of Harvard University. Faculty Research Working Papers have not undergone formal review and approval. Such papers are included in this series to elicit feedback and to encourage debate on important public policy challenges. Copyright belongs to the author(s). Papers may be downloaded for personal use only. 


\title{
On the Philosophy of Group Decision Methods I: the Non-Obviousness of Majority Rule
}

\author{
Mathias Risse \\ John F. Kennedy School of Government, Harvard University \\ October 31, 2008 \\ (forthcoming in Philosophical Compass)
}

\begin{abstract}
Majority rule is often adopted almost by default as a group decision rule. One might think, therefore, that the conditions under which it applies, and the argument on its behalf, are well-understood. However, the standard arguments in support of majority rule display systematic deficiencies. This article explores these weaknesses, and assesses what can be said on behalf of majority rule.
\end{abstract}

1. "Unanimity is impossible; the rule of a minority, as permanent arrangement, is wholly inadmissible; so that, rejecting the majority principle, anarchy or despotism in some form is all that is left.” ${ }^{1}$ So Lincoln said in what probably was one of his less insightful moments. Alas, opposition to majority rule may come from champions of alternative decisions rules who cheer for neither anarchy nor despotism, but for rules whose rationale does not focus on whether it is a majority or a minority that wins. Much is at stake. When groups make decisions, there usually are different ways of doing so, each with its own merits, and none of the more reasonable ones committed to despotism or anarchy. For any method a group could use, some are left losers who would be faring better had the group adopted a different, prima facie also plausible rule. It is therefore important to explore under what conditions we can single out a uniquely most plausible decision method, and how to argue for particular methods in the first place. These questions arise with much urgency for majority rule.

\footnotetext{
${ }^{1}$ Quoted in Mayo (1960), p 179. Many thanks to Tony Laden and two anonymous referees for helpful comments.
} 
One reason, perhaps, why philosophers have neglected this topic recently draws on the prominence of work on "Deliberative Democracy," according to which democracy is a social ideal because of the significance of suitably conducted deliberation for the justification of political decisions. In this conception, the relevance of deliberation is often emphasized at the expense of decision making by aggregating votes, or by fair division. ${ }^{2}$ Yet conflicts of values that cannot be reconciled within single lives, single decisions of deliberating bodies, or single constitutions constrain what deliberation can achieve, inevitably forcing groups to make decisions in the presence of irresolvable disagreement.

If a group must choose between options $\mathrm{A}$ and $\mathrm{B}$, deciding by majority rule means choosing the option that the larger number supports (where we can leave open what to do when $\mathrm{A}$ and $\mathrm{B}$ are on a par). If the group has to make a decision involving more than two options (say, $A_{1}$ through $A_{n}$ ), it is challenging to say precisely what majoritarian decision making amounts to. Phenomena such as the Condorcet Paradox and Arrow's Impossibility Theorem lurk here, results from Social Choice Theory that show that even the definition of majority rule for the case of more than two options is problematic. We deal with these phenomena in a companion piece ("On the Philosophy of Group Decision Methods II: Alternatives to Majority Rule”). For now, let us say that majority rule for more than two options ranks $A_{1}$ through $A_{n}$ in such a way that the top-ranked option beats all others in a pairwise vote, the second-ranked beats all others except the top-ranked, and so on - if indeed there is such a top-ranked, second-ranked, etc., candidate. If not, we

\footnotetext{
${ }^{2}$ See for instance, Spitz (1984) for a skeptical view of majority view when seen in the context of deliberative democracy. For an investigation of majority rule within democratic theory, see Christiano (1996).
} 
need some other rationale for choosing a ranking, but for now we assume this problem can be solved satisfactorily. ${ }^{3}$ (I use the term "options" for whatever is ranked: options could be candidates running for office, courses of action, houses for purchase, etc.)

Majority rule is often adopted almost by default. The $17^{\text {th }}$ century philosopher Hugo Grotius captured a widely shared view by claiming that "the majority would naturally have the right and authority of the whole. ${ }^{4}$ Political thinkers from John Locke to Hannah Arendt have shared this assessment. This article and the companion piece seek to show why philosophical reflection on group decision methods generally and majority rule in particular is important and rewarding. One might think that, given its ubiquity, the conditions under which majority rule applies have long been understood. But some challenges in this area have barely been tackled. Section 2 offers a rationale for majority rule and articulates several complaints about it. Section 3 discusses the standard arguments for majority rule. Crucially, these arguments fail to settle the complaints because they address defenders of some kind of minority rule. Yet the strongest competitors to majority rule are neither explicitly anti-majoritarian nor pro-minoritarian, but both a-majoritarian and a-minoritarian: they advise groups in a manner that neither always endorses nor always dismisses what "the majority wants," but sets it aside and

\footnotetext{
${ }^{3}$ See Riker (1982), chapter 4 for an exploration of different ways of doing this. To illustrate briefly how there could be no such ranking, consider the following situation. Suppose three people need to rank options A, B, and C. One ranks them (A, B, C), one (B, C, A), and one (C, A, B). In that case no option beats both others in pairwise votes. This is the Condorcet Paradox: each individual has a ranking, but the group does not. Kenneth Arrow's (1951) Impossibility Theorem captures this phenomenon in more generality, showing that there is no decision method that transforms individual rankings into a collective ranking and satisfied a number of prima facie plausible conditions. For a comprehensive recent account of Social Choice Theory, see Austen-Smith (1998) and (2005).

${ }^{4}$ Cf. De Jure Belli ac Pacis, Bk 2, chap 5, sec 17 (any edition).
} 
focuses on a different rationale that does not involve counting heads. Section 4 proposes a rationale for majoritarian decision making that takes these competitors into account. At one point, the case for majoritarian decision making is plainly pragmatic. Much is left to be said, my purpose being to trigger more interest in these questions. The companion piece looks at some competitors in more detail and engages with some of the more technical debates in more depth. ${ }^{5}$

2. If a decision problem does not offer an immediate choice between two options, it is often transformed to allow for pairwise voting. For example, if an assembly considers an amendment to a proposal, the assembly members' views are appropriately captured by rankings of three options: status quo, proposal, and amended proposal. Yet assemblies do

\footnotetext{
${ }^{5}$ Throughout I draw on earlier work: Risse (2001) and (2004). The companion piece discusses fair division methods in more detail, but since I occasionally refer to them, let me explain some essentials. Fair division theories consider the following type of situation: There are goods to which several parties make claims, or "bads" with regard to which they have obligations. These goods or bads may be divisible (land, costs, or, in the classic illustration, a cake) or, for practical purposes, indivisible (houses, children for custody, seats in congress); they may be concrete (land) or abstract (honors, positions, or, on the negative side, household chores, military service, taxation). Although the field is called "fair division," it is best understood as dealing with the arbitration of competing claims, which may not always literally "divide" anything. For instance, a dispute about a corner office may be resolved by a seniority principle, which would neither entail that the office be divided, nor that everybody's claims succeed at least to some extent. Or consider a custody dispute. A child cannot be divided, but a common solution is to adopt a rotation scheme: the child spends some time with the father and some time with the mother. What is divided is the child's time. Or suppose one city must provide a site for a waste dump. This city could be compensated by other cities so that they all carry an equal burden. Compensation and rotation fail to apply when the question is who should receive a kidney transplant, or which survivor should be sacrificed for the sake of the others. Under such circumstances, priority criteria could be set up (preferably in an impartial and consistent way), and among those with equal priority, a lottery might determine the ranking. Randomization, like rotation and compensation, associates an indivisible good with a closely related divisible good to which ideas of fair division apply straightforwardly. Proportionate-representation approaches to voting also capture an idea of fair division. The case in their support has been made for instance by Guinier (1994), who emphasizes the unfairness inflicted by majority rule on persistent minorities. A $19^{\text {th }}$ century articulation of that standpoint is due to John Calhoun (see Calhoun (2007). One problem we will not discuss but that has recently attracted much attention is the so-called n Discursive Dilemma. This dilemma shows that majority voting on logically connected issues can generate an inconsistent set of judgments or goals. Suppose a group of three, $\mathrm{X}, \mathrm{Y}$ and $\mathrm{Z}$, vote on whether $\mathrm{A}$, whether $\mathrm{B}$ and whether $\mathrm{A} \& \mathrm{~B}$. $\mathrm{X}$ and $\mathrm{Y}$ vote for $\mathrm{A}, \mathrm{Y}$ and $\mathrm{Z}$ for $\mathrm{B}$, so that only Y will support A\&B. So majority rule commits the group to A, B and (not-A\&B). See List (2006) for an accessible introduction; see also Bovens and Rabinowicz (2006).
} 
not often solicit such rankings. Instead, they break decisions down into pairwise votes. Normally, they first put up the proposal for a vote against the amendment, and then the winner against the status quo. Another example of how decisions are broken down to make pairwise voting decisive is run-off elections. If no candidate wins a majority in the first round, the two top candidates enter a run-off election.

Yet other decision rules too are reasonable in such situations: choosing among three options, individuals may assign two points to their first-ranked option, one to the second-ranked, and zero to the lowest, while the group decides by summing over these numbers and by ranking the options beginning with the one with the highest number. (For n options, assign n-1 to the highest-ranked option, etc.) This is the Borda count, named after an $18^{\text {th }}$ century French nobleman, the Count de Borda. To see how the Borda count and majority rule deliver different results, suppose we have the following rankings: $(\mathrm{X}, \mathrm{Y}$, A, B, C); (Y, A, C, B, X); (C, X,Y, A, B); (X, Y, B, C, A); (Y, B, A, X, C). Borda selects Y, but $\mathrm{X}$ beats all others in pairwise votes. ${ }^{6}$ The rationale for Borda differs from the rationale for majority rule: What recommends the Borda winner is that it appears highest on average across rankings. There has been a debate between defenders of that approach and defenders of majoritarian decision making since the $18^{\text {th }}$ century.

Why choose majority rule? A passage from chapter 16 of Thomas Hobbes' Leviathan still appears in contemporary justifications of majority rule:

And if the Representative consist of many men, the voyce of the greater number, must be considered as the voyce of them all. For if the lesser number pronounce (for example) in the Affirmative, and the greater in the Negative, there will be Negatives more than enough to destroy the affirmatives; and thereby the excesse of Negatives, standing uncontradicted, are the only voyce the Representative hath.

\footnotetext{
${ }^{6}$ For the example, see Riker (1982), p 83.
} 
According to Waldron's (1999) interpretation, the views of any two disagreeing individuals cancel each other out so that the majority view remains unopposed when all dissent has been "used up.” Waldron takes this literally: a member of party $\mathrm{P}_{1}$ presents an argument for their view; then a member of $\mathrm{P}_{2}$ presents an argument for theirs, etc. Waldron holds that, under such circumstances, "more" has been said on behalf of the view of the majority. ${ }^{7}$ Suppose "we" and "they" are two adversarial schools of thought in a philosophy department. They have the majority. The department must decide whether to hire a philosopher from their camp or from ours. The factions taking turns, everybody states their view. Since they are more, their view remains ultimately unopposed. But we may have several objections.

To begin (Complaint 1), it is wrong that "more" has been said on their behalf because they outnumber us. Arguments of equal strength may cancel each other out, but individuals do not do so merely because they support different views. Or we may care more about the outcome (Complaint 2). Maybe they prefers hiring somebody from their camp, but only slightly so, whereas we care deeply about getting our candidate hired. Majority rule fails to consider relevant information: the intensity of preferences. One may respond that how much anybody "cares" is irrelevant in all but very informal setting. But

\footnotetext{
${ }^{7}$ See Waldron (1999), p 138. Waldron (1999) is an important contemporary justification of majority rule; see Risse (2004) for a detailed engagement with Waldron. Section 96 of John Locke's Second Treatise of Government is another locus classicus for majority rule: "For when any Number of Men, by the consent of every individual, made a Community, they have thereby made that Community one Body, with a Power to Act as one Body, which is only by the will and determination of the majority. For that which acts any Community, being only the consent of the individuals of it, and it being necessary to that which is one body to move one way, it is necessary the Body should move that way whither the greater force carries it, which is the consent of the majority: or else it is impossible it should act or continue one Body, one Community, which the consent of every individual that united into it, agreed that it should; and so every one is bound by that consent to be concluded by the majority." Waldron (1999) is among the champions of the passage; see Kendall (1941) for a classic treatment. Risse (2004) argues that this passage does not support majority rule but fair division methods.
} 
consider Complaint 3. Suppose we rank applicants by having each individual assign points between 1 and 20 to the candidates, evaluating their skills, and by then forming averages. Our top candidate receives a high average, but theirs does not. We claim majority rule treats us unfairly by not considering such information.

Or suppose we find their candidate unacceptable, whereas they consider ours appointable (Complaint 4). Once more we lose important information by using majority rule. We may suggest approval voting: each faculty member gives a vote to each candidate she regards as appointable. Our candidate would win. Finally, suppose we make up $40 \%$ of the department, and they $60 \%$ (Complaint 5). Yet majority rule sets our chances at getting our candidate hired at $0 \%$, and theirs at $100 \%$, thus refusing us proportionate consideration. If we make more hires, we can adopt a fair division scheme (e.g., hiring four in ten from our camp). Otherwise, we may ask for a $40 \%$ chance at having our candidate hired.

3. Given these complaints, let us see what arguments commonly support majority rule:

Minority vs. Majority: This view is well expressed in this quotation: "It seems scarcely necessary to prove that, if the decision is not to be unanimous - if the concurrence of all the members of the body is not required - it must be made by a majority, and not by a minority, however determined. If a minority could prevail over the majority, those who were in favor of a proposition would vote against it, or would abstain from voting in order to insure a majority to their side of the question. Besides, there would be no inducement to discuss a question, if, by converting a person to our opinion, you did not strengthen our side (...) when the votes came to be counted."

\footnotetext{
${ }^{8}$ Cf. Lewis (1849), p 207. Barry (1991), p 27 points out that "by something akin to the principle of insufficient reason" it should be majorities rather than minorities ruling.
} 
Maximization: Majority rule maximizes the number of people who exercise selfdetermination. This argument evidently generalizes to whichever property one thinks is expressed in the act of voting or realized by winning an election. ${ }^{9}$

Respect: Majority rule is a good way of expressing respect for people in the circumstances of politics, i.e., in circumstances in which in spite of remaining differences (even after deliberation) a common view needs to be found. Majority rule allows each person to remain faithful to his conviction, but still to accept that a group decision needs to be made.

Condorcet's Jury Theorem: Supposes it makes sense to speak of being right or wrong about political decisions. Suppose $\mathrm{n}$ agents choose between two options; that each has a probability of $\mathrm{p}^{>1 / 2}$ of being right; and that their probabilities are independent of each other (i.e., they make up their minds for themselves ${ }^{10}$ ). Then, as $\mathrm{n}$ grows, the probability of a majority's being right approaches 1 .

May's Theorem: May shows that majority rule for two options and an odd number of voters is the only rule satisfying four reasonable conditions: Decisiveness, that is, for any two options, exactly one must be chosen; anonymity: the outcome does not depend on which specific people are for or against an alternative; neutrality: no alternative has a built-in advantage according to the procedure; positive responsiveness: if the group is initially indifferent between options $\mathrm{A}$ and $\mathrm{B}$, and some persons change their minds in favor of (say) $\mathrm{A}$, whereas nobody changes his or her mind in favor of $\mathrm{B}$, then the decision procedure opts in favor of $\mathrm{A}$. This argument is intriguing because the conditions are elementary. ${ }^{11}$

Yet these arguments have problems that display a systematic pattern: Either they assume collective decision making must be done in ways that already exclude some of the more serious competitors to majority rule (e.g., the Borda count, methods that assign

\footnotetext{
${ }^{9}$ Cf. Dahl (1989), p 138. For the argument from respect, see Waldron (1996).

10 This criterion was violated (e.g.) in the Roman Senate: senators could change their vote after hearing the announcement of everybody else's vote (cf. Gierke (1913)). For discussion and extensions of Condorcet's theorem, cf. Grofman et al. (1983), Estlund and Waldron (1989). For discussion of the epistemic conception of democracy, which most prominently needs that assumption, cf. Cohen (1986), Copp (1993), Estlund (1993). For a recent discussion, see Estlund (2008). Jean-Jacques Rousseau's On the Social Contract can arguably be read as advancing majority rule as the voice of the general will.

${ }^{11}$ Cf. Ackerman (1980), chapter 9, and Rae and Schickler (1997) for a discussion of majority rule in light of May's theorem. The imposition of decisiveness makes sense only since we are assuming an odd number of voters. This assumption is no serious restriction on whatever the usefulness of theorem would be; for discussion, see Taylor (1995), chapter 10.3.
} 
points to candidates, or fair division methods); or these arguments support other decision rules as well. In the latter case, the argument is question-begging by differentiating insufficiently among decision rules, and in that sense is too broad. In the former case, the argument is question-beginning (vis-à-vis certain important competitors) by making too many presuppositions about feasible rules, and in that sense is too narrow. These presuppositions may include some or all of the following: (a) the information used by the decision rule is limited to information about the relative standing of any two options in rankings; (b) the method restricts the actual voting to pairs of options, (c) there is a commitment to using aggregation methods at the exclusion of other decision procedures, in particular fair division. Being too narrow or too broad, these arguments do not adequately respond to the complaints registered above. ${ }^{12}$

Let me demonstrate these weaknesses argument by argument. May's theorem only applies when groups decide on two options. The theorem also presupposes that the only information relevant for the decision is information regarding who prefers which option. Thus May’s theorem only addresses an opponent who, if only two options are assessed and if the only relevant information is information about the relative standing of pairs of options, suggests that the group follow a minority or a supermajority. May's theorem does not respond to the complaints above, since all except Complaint 1 object to its presuppositions.

\footnotetext{
${ }^{12}$ One might object that fair division methods do not count as competitors to majority rule. Distinguish between collective choice rules and social welfare functions. The former are rules used by collectives to make decisions; the latter are formulas employed to decide how well various proposals serve the interests of a group (cf. Sen (1970)). What counts as a good collective choice rule need not count as a good social welfare function, and vice versa. A paradigmatic example of a social welfare function that might be less plausible as a collective choice rule is utilitarian aggregation - and one might argue that fair division methods ought to be so classified as well. But this would be moving too fast. Voting methods based on ideas of proportionate representation are just one example of how a fair division method operates as a collective choice rule. The question we are pursuing is: under what conditions should they be?
} 
The argument from respect is too broad. Fair division procedures or aggregative decision procedures using more than information about the relative standing of pairs permit an equally strong case on behalf of respect. Defenders of a point system such as the one in Complaint 3 may argue the best way of taking people seriously is to give weight to the strength of their views. Defenders of Borda could insist that the best way of respecting individuals is to consider all the information provided by their rankings, not merely part of it (ranking in pairs), as majority rule suggests. The argument from respect only helps against proponents of rather odd rules, such as selecting candidates born on a warmer day than others.

Majorities vs. Minorities is "too narrow:" this argument presupposes that decisions are made by methods that explicitly champion either the majority or a minority. Maximization is both "too broad" and "too narrow:" On the one hand, it is easy to find a quality that alternative rules maximize. Borda ranks options by their average standing in the ranking. In that sense, Borda maximizes agreement among rankings, not acts of selfdetermination. On the other hand, if acts of self-determination are captured by counting heads, the argument fails to convince opponents insisting that voting methods should use more than information regarding the relative standing of options. Finally, the Jury Theorem is "too narrow" because it assumes that we are merely ranking options. ${ }^{13}$

One might say it is tautological, if there are only two options and no tie, that either a majority or a minority wins. Thus all arguments for majority rule speak against any option favored by a minority, and support the other option instead. Yet resistance

\footnotetext{
${ }^{13}$ The theorem in its original form applies to two options, but has been generalized; see Young (1988).
} 
against arguments for majority rule is not motivated by support for particular minorities.

Instead, there are other rules that sometimes let a minority decide and sometimes a majority, but this is irrelevant to their rationale.

Or one might say that majority rule indeed only applies to two options, but insist that a great many decision situations are of that sort. But, again, such situations are common largely because decisions are transformed into binary votes. Yet such transformations beg the question especially against so-called positional accounts. Like majority rule, such accounts merely use information about relative standing, but do not dissect decisions into pairwise votes. Rather, they take into account some or all of the information about whole rankings. They introduce some measure of "aheadness" of options within rankings, for instance, by assigning points to the candidates depending on where they appear in the ranking. Examples are (once again) the Borda count, but also plurality rule (the option with most votes wins), and approval voting (each individual has more than one vote). ${ }^{14}$ Any reduction to scenarios where pairwise voting is decisive would have to be justified vis-à-vis methods that omit such reductions. All methods just mentioned coincide with majority rule for two options, so the differences between these approaches become clear only once we turn to scenarios with more than two options.

\footnotetext{
${ }^{14}$ Cf. (e.g.) Riker (1982), chapter 4. Riker shows in particular how these different rules can lead to different results from consecutive majoritarian votes (and that they also do not tend to lead to the same results). Notice that the point is not that positional measures are each using "more" information than pairwise majority rule. Instead, the point is that they are motivated differently: they are concerned to use some or all of the information about whole rankings and do not break choices down into sequential pairwise votes. Borda uses all such information; approval voting and plurality rule use some, and in fact plurality rule uses only information about first places (Riker (1982), p 81). To apply the issue just discussed to May's Theorem: One might say that, if there are more than two options, May's Theorem can be applied pair-bypair, as May (1952) himself suggested. But this would be question-begging against positional accounts as just sketched. Goodin and List (2006) offer a generalization of May's Theorem for a scenario where only each voter's top choice is solicited. This generalization supports plurality rule. But this generalization too is question-begging against Borda by its very set-up since Borda requires more informational input.
} 
4. We can learn from this discussion that there are strong arguments for majoritarian decision making whenever it is reasonable (a) to use merely information about the relative standing of any two options in individual rankings, (b) to restrict the voting to pairs of options, and (c) to use aggregation methods at the exclusion of other decision procedures, in particular fair division. Once (a), (b), and (c) are granted, the standard arguments for majority rule can do their work. So justifying the use of majority rule means identifying the reason for or circumstances under which they ought to be imposed.

Let us begin with (a). It is hard to find decision processes for which the only relevant information is of this sort. Often, for instance, we would like to be able to use information about the strength of preferences, or use more fine-grained judgments, say, as provided by a point-system. Yet what matters for the choice of an aggregation rule is not merely what information should be used given the purpose of the decision process, but also what information one can reliably solicit. There are two concerns. On the one hand, the more fine-grained information we admit, the more interpersonal comparability among individuals is problematic. This matter is notorious when it comes to welfare, but it also bears on judgment contexts. It is hard for me to compare to my standards a B+ given by somebody I do not know.

The other problem is manipulability. Suppose we are considering several candidates at the last stage of our hiring process. Many colleagues think highly of my second-ranked candidate, rendering bleak the prospects of my first-ranked. But her chances increase if I vote as if my second-ranked candidate were lower in my ranking. I vote “strategically," falsifying one segment of my ranking to boost another. If we use more fine-grained information, I can achieve even more by falsifying my true views: if I 
convince you that watching your movie would leave me dysfunctional though I really

like it only slightly less than mine, chances of us watching my movie are probably

increasing. The more-fine-grained information the aggregation admits, the more it is prone to problems of interpersonal comparability, and to manipulation. ${ }^{15}$

The credibility of a group judgment decreases to the extent that we have difficulties comparing individual judgments, and to the extent that we are unsure whether individuals express their true views (mutatis mutandis for group welfare). No matter how appropriate information beyond that about relative standing of options is with regard to the purpose of the decision process, such considerations are counterbalanced by worries about reliability. The problem may not be that people misrepresent their views, but that others cannot be sure they do not, and thus find their own best response is to falsify information. Such mutual uncertainty increases the chances that information really is unreliable. To the extent that reliability is a problem, there is a pro tanto argument for using only information about the relative standing of options in rankings. ${ }^{16}$

${ }^{15}$ A word of caution: There is a formal literature on "strategy-proofness." As is intuitively clear, majority voting for a binary choice is strategy-proof, that is, there is never a chance of promoting the candidate you prefer more by voting for the candidate you prefer less. But according to the Gibbard-Satterthwaite theorem, for more than two options the only strategy-proof voting methods are dictatorial. (See Gibbard (1973) and Satterthaite (1975).) Cf. Moulin (1988), chapter 10, for an overview. "Manipulation" is a contested term, for it is unclear that individuals are acting immorally by reporting untruthfully on their preferences. For this reason, the more neutral term "strategic voting” tends to be used. My discussion of strategic voting and of more or less fine-grained information above proceeds at an intuitive level, which I think is sufficient for our purposes. Statements such as "the more fine-grained information we use, the more the voting-methods are prone to manipulation" are qualitative assessment whose plausibility is demonstrated by examples such as those given in the text. However, as far as I know, there is as of now no formal work that investigates whether aggregation methods that use more fine-grained information are in any precise sense more prone to manipulation, and what I say about this above should be taken with this qualification. But even if the point about manipulability is taken out of the discussion, the overall approach to a justification of majority rule that I present in this section would still work because this point is one in two made in support of the restriction to using only information about the relative standing of any two options in individual rankings.

${ }^{16}$ How serious these two problems are depends on the context. We do not normally consider it problematic that grades from different instructors may be hard to compare, since it all "averages out" in the Grade Point 
As far as the restriction to pairwise voting is concerned (condition (b)), we can appeal to the virtues of reducing complexity. Group decisions lose credibility to the extent that the individuals do not make a carefully considered decision. Other decisions may then easily have been made. Since such concerns arise the more easily the more complex the decision scenario is, there is pressure to transform the decision situation into one where pairwise voting can decide. Recall voting on proposals. Each amendment doubles the number of options: each proposal-cum-amendments can be supplemented with the new amendment, or not. Different options may also be hard to compare if amendments make different points. Since committees operate under time constraints, the advantage of complexity reduction is obvious. Similar considerations apply to elections with more than two candidates. Note that this argument is significantly weaker than the argument for the restriction to information about relative standing of options. Considerations of interpersonal comparability and manipulability inherently constrain group decision making, whereas worries about complexity operate at a pragmatic level. It is unclear to what extent complexity considerations justify or merely explain the restriction to pairwise votes. But it seems nothing stronger can be said here.

What about the restriction to aggregative decision methods (condition (c))? Let me discuss merely why it might be legitimate to exclude fair division methods. The problem with applying these methods is that, often, none is sufficiently salient for us to resolve a dispute about various proposals as to what fairness requires. Recall the hiring scenario. Frequently we will not have two so strongly divided factions, and thus no

Average. However, we would not want to use a judgment scale with values between 0 and 10 for, say, gubernatorial contests, and I submit that that is partly because of problems of interpersonal comparability and manipulability. 
factions that are co-claimants in a fair-division scheme. The minority in an election may not have the kind of identity that would make it reasonable, say, to compensate "them." But even if there were a group with a sufficiently developed identity, the division problem itself may not render one solution salient. If we have to fill a position for some years, we might do so by lottery, with the weights reflecting the strength of conflicting views. Another suggestion is that some rotation or compensation scheme be adopted. Yet if no solution is salient, no solution has been found. Such a lack of salience is likely under circumstances of radical and persistent disagreement, that is, under those circumstances that recommend fair division methods in the first place.

For these considerations to render the arguments for majority rule most readily applicable, they would actually have to show that the group's decision situation can sensibly be set up in such a way that a single vote between two options is decisive which will often be implausible. If there are still more than two options on which people need to vote, these considerations will not rule out Borda. ${ }^{17}$ There is, however, one additional argument for majority rule: there is much merit to having a default group decision method. For different group decision rules invariably lead to different results, making some people losers who would be winners if a different, but equally reasonable voting method were chosen. If reflection on the decision situation makes various decision rules appear reasonable, a "default rule" is immensely beneficial. Reference to the default-character of one decision rule can serve as a "tie-breaker" if there is no point of view from which to arbitrate conclusively among different rules. Part of the justification

\footnotetext{
${ }^{17}$ In that case, the voting process will also be susceptible to strategic voting/manipulation. The companion piece argues that the Borda count and majoritarian decision making are reasonable methods under the same conditions. For the case of two options, they coincide.
} 
for majority rule's being that default rule is that it is free from troublesome concerns of interpersonal comparability and manipulability and makes for a simple procedure. This argument, in addition to what we have said on behalf of condition (a), (b), and (c), is all we can reasonably say in favor of majority rule in general. In many cases (surely in many more cases than one might have thought given the ubiquity of majority rule), the considered judgment should be that majority rule is inappropriate. There is also room for other rules, and unless different arguments for majority rule are available, we need to increase our awareness that the best case for majority rule is much more pragmatic and less principled than one might have thought.

\section{Literature}

Ackerman, Bruce. 1980. Social Justice and the Liberal State. New Haven: Yale University Press

Arrow, Kenneth. 1963. Social Choice and Individual Value. $2^{\text {nd }}$ edition. New Haven: Yale University Press

Austen-Smith, David, and Jeffrey Banks. 1998. Positive Political Theory I: Collective Preference. Ann Arbor: University of Michigan Press

Austen Smith, David, and Jeffrey Banks. 2005. Positive Political Theory II: Strategy and Structure. Ann Arbor: University of Michigan Press

Barry, Brian. 1991. “Is Democracy Special?” In: Democracy and Power, Oxford: Clarendon

Bovens, Luc, and Wlodek Rabinowicz. 2006. "Democratic Answers to Complex Questions: An Epistemic Perspective.” Synthese 150 (1): pp 131-153 
Calhoun, John. 2007. A Disquisition on Government. Edited by Lee Cheek. South Bend: St. Augustine’s Press

Christiano, Thomas. 1996. The Rule of the Many. Fundamental Issues in Democratic Theory. Boulder: Westview

Cohen, Joshua.1986. “An Epistemic Conception of Democracy.” Ethics 97: 26-38

Copp, David. 1993. “Could Political Truth be a Hazard for Democracy?” In Copp at al (1993)

Copp, David, Jean Hampton, and John Roemer (eds.). 1993. The Idea of Democracy. Cambridge: Cambridge University Press

Dahl, Robert. 1989. Democracy and Its Critics. New Haven: Yale University Press

Estlund, David. 1993. “Making Truth Save for Democracy”. In Copp et al. (1993)

Estlund, David and Jeremy Waldron. 1989. "Democratic Theory and the Public Interest: Rousseau and Condorcet Revisited.” American Political Science Review 83, $1317-1340$

Estlund, David. 2008. Democratic Authority: A Philosophical Framework. Princeton: Princeton University Press

Gibbard, Allan. 1973. "Manipulation of Voting Schemes: A General Result.“ Econometrica 41 (4): pp 587-601

Gierke, Otto von. 1913. “Über die Geschichte des Majoritätsbegriffes”. In Essays in Legal History. Ed. P. Vinogradoff. Oxford: Oxford University Press 
Goodin, Robert, and Christian List. 2006. “A Conditional Defense of Plurality Rule: Generalizing May's Theorem in a Restricted Informational Environment.” American Journal of Political Science 50 (4): pp 940-949

Grofman, Bernard, Guillermo Owen, and Scott Feld. 1983. "Thirteen Theorems in Search of the Truth.” Theory and Decision 15: 261-278

Guinier, Lani. 1994. The Tyranny of the Majority. Fundamental Fairness in Representative Democracy. New York: Free Press

Kendall, Willmoore. 1941. John Locke and the Doctrine of Majority Rule. Urbana: University of Illinois Press

Lewis, George. 1849. On the Influence of Authority in Matters of Opinion. London: Parker

List, Christian. 2006. "The Discursive Dilemma and Public Reason.” Ethics 116(2): pp 362-402

May, Kenneth. 1952. “A Set of Independent Necessary and Sufficient Conditions for Simple Majority Decision”. Econometrica 20: 680-684

Mayo, Henry. 1960. An Introduction to Democratic Theory. Oxford: Oxford University Press

Moulin, Hervé. 1988. Axioms of Cooperative Decision Making. Cambridge: Cambridge University Press

Mueller, Dennis (ed). 1997. Perspectives on Public Choice. Cambridge: Cambridge University Press

Rae, Douglas and Eric Schickler. 1997. “Majority Rule.” In Mueller (1997)

Riker, William. 1982. Liberalism Against Populism. San Francisco: Freeman 
Risse, Mathias. 2001. “Arrow’s Theorem, Indeterminacy, and Multiplicity Reconsidered”. Ethics, Vol. 111, pp 706-734

Risse, Mathias. 2004. “Arguing for Majority Rule.” Journal of Political Philosophy, Vol. 12, No. 1, pp 41-64

Satterthwaite, Mark. 1975. “Strategy-Proofness and Arrow’s Conditions: Existence and Correspondence Theorems for Voting Procedures and Social Welfare Functions.” Journal of Economic Theory 10: pp 187-217

Sen, Amartya. 1970. Collective Choice and Social Welfare. San Francisco: Holden Day

Spitz, Elaine. 1984. Majority Rule. Chatham: Chatham House

Taylor, Alan. 1995. Mathematics and Politics. New York: Springer

Waldron, Jeremy. 1996. "Legislation, Authority, and Voting.” Georgetown Law

Journal, Vol. 84 (1996): 2185-2214

Waldron, Jeremy. 1999. The Dignity of Legislation. Cambridge: Cambridge University Press

Young, Peyton. 1988. “Condorcet’s Theory of Voting”. American Political Science Review 82: 1231-1244 